\title{
My Life as an Estimate Writ in Stone
}

When I want to be by myself it really means sell everything, unplug the radio, roll me in Tuscan red to Berlin so I can level the field, chew a finger from the glove. Entire blocks were left ruined in a month. I didn't want to come but I did, denied a key to the city, so I settle for a room above Rosa Luxemburg, brood \& grumble from the underground, smoke a rotten tooth the mice won't touch. Apples turn in the baskets, the flag in tatters, a river laps the frame of a door where I ride two wheels into the current. My estimations may be wrong but I've never murdered: for three days in the fourth grade I considered two girls, swallowed the lock of a mistress who didn't sing. Our mouths joined leather \& steel, the figure who bore my polished features, the right eye failing while I occupied the city with my left. Here, I'll try the poison on the dog first, take a rubber raft, make a run at the barbed fence. I'll come to no one's rescue. Who she thought she was, the paper swan on the paper lake, wasn't who she was.

If she crawled on all fours she'd have bitten. 